\title{
Qualidade e teores de nutrientes de palmeira-rápis em substrato com fibra de coco
}

\author{
Flávia dos S Alvesi'; Janie M Jasmimi ; Almy JC de Carvalho'; José Tarcísio L Thiébaut ${ }^{2}$ \\ 'UENF-CCTA-LFIT Av. Alberto Lamego, 2000, 28013-602, Campos dos Goytacazes-RJ; ${ }^{2}$ UENF-LEAG; alves-flavia@ig.com.br; \\ janie@uenf.br
}

\begin{abstract}
RESUMO
As avaliações foram realizadas em quatro substratos compostos de mistura de fibra de coco triturada (FC) e substrato comercial Plant$\max \mathrm{HT}^{\circledR}(\mathrm{SC})$, nas proporções de $0,25,50$ e $75 \%$ de $\mathrm{FC}$, em vasos com capacidade para $35 \mathrm{~L}$, em delineamento de blocos ao acaso, com quatro repetições e três vasos por parcela, com uma planta por vaso. A adubação das plantas foi feita alternando-se, a cada três meses, 25 $\mathrm{g}$ de 4-14-8 com $10 \mathrm{~g}$ de uréia por vaso, a partir do plantio e durante os 24 meses do período experimental. O crescimento foi avaliado medindo-se a altura da haste inicial (da base do caule à inserção da última folha completamente expandida), número de folhas da haste inicial, número de perfilhos, número de folhas dos perfilhos, altura dos perfilhos e teores de nutrientes da última folha completamente expandida da haste inicial. A qualidade foi avaliada através de análise sensorial visual, baseado nos critérios "gostei" (muito ou pouco) e "compraria" (sim ou não). Não houve diferença entre os tratamentos sobre as características de crescimento, exceto para o número de folhas da haste inicial. As plantas com melhor aceitação foram aquelas cultivadas na mistura com $50 \%$ FC e $50 \%$ SC. Nenhuma das plantas apresentou sintoma visual de deficiência de nutrientes, sendo os teores foliares encontrados em plantas sadias com padrão de qualidade para comercialização de: 17,80 - 18,29 $\mathrm{g} \mathrm{kg}^{-1}$ de N; 0,66 - 0,81 $\mathrm{g} \mathrm{kg}^{-1}$ de NO${ }^{-3} ; 2,02$ - 2,34 $\mathrm{g} \mathrm{kg}^{-1}$ de P; $18,11-20,40 \mathrm{~g} \mathrm{~kg}^{-1} \mathrm{de}$ $\mathrm{K} ; 11,63$ - 13,84 $\mathrm{g} \mathrm{kg}^{-1} \mathrm{de} \mathrm{Cl} ; 2,69$ - 4,04 $\mathrm{g} \mathrm{kg}^{-1} \mathrm{de} \mathrm{Ca} ; 1,61$ - 2,07 g $\mathrm{kg}^{-1}$ de $\mathrm{S} ; 1,98-2,64 \mathrm{~g} \mathrm{~kg}^{-1} \mathrm{de} \mathrm{Mg}$.
\end{abstract}

Palavras-chave: Rhapis excelsa, casca de coco, adubos.

\begin{abstract}
Quality and nutrient content of lady palm in coconut fiber substrate

It was evaluated the quality and nutrient content of lady palm in four substrates made up of a mixture of shredded coconut fiber (FC) and commercial substrate Plantmax $\mathrm{HT}^{\circledR}$ (SC), in proportions of $0,25,50$ and $75 \%$ of FC, in 35 liters containers, in a randomized block experiment with four replicates and three pots per plot, with one plant per pot. The plants were fertilized every three months alternating $25 \mathrm{~g}$ of 4-14-8 with $10 \mathrm{~g}$ of urea per pot, at planting and throughout the 24 months of the experimental period. Growth was evaluated by measuring the height of the initial stem (from the stem base to leaf insertion of the most recently expanded leaf), number of leaves in the original stem, number of offsets, number of leaves in offsets, offset height and nutrient content of last completely expanded leaf in the initial stem. The quality was evaluated by visual sensorial analysis using the criteria "I liked it" (a lot or a little) and "I would buy it" (yes or no). There was no significant difference on the growth characteristics among treatments, except on the number of leaves of the initial stem. Plants with the best acceptance were those grown in the mixture $50 \% \mathrm{FC}$ and $50 \% \mathrm{SC}$. None of the plants showed visual nutrient deficiency symptoms; the leaf nutrient content of healthy plants with market quality standards were: $17.80-18.29 \mathrm{~g} \mathrm{~kg}^{-1}$ of $\mathrm{N}$; $0.66-0.81 \mathrm{~g} \mathrm{~kg}^{-1}$ of $\mathrm{NO}^{-3} ; 2.02-2.34 \mathrm{~g} \mathrm{~kg}^{-1}$ of P; $18.11-20.40 \mathrm{~g} \mathrm{~kg}^{-1}$ of $\mathrm{K} ; 11.63-13.84 \mathrm{~g} \mathrm{~kg}^{-1}$ of $\mathrm{Cl} ; 2.69-4.04 \mathrm{~g} \mathrm{~kg}^{-1}$ of $\mathrm{Ca} ; 1.61-2.07$ $\mathrm{g} \mathrm{kg}^{-1}$ of $\mathrm{S} ; 1.98-2.64 \mathrm{~g} \mathrm{~kg}^{-1}$ of $\mathrm{Mg}$.
\end{abstract}

Keywords: Rhapis excelsa, coconut husk, fertilizers.

(Recebido para publicação em 20 de fevereiro de 2009; aceito em 10 de dezembro de 2009) (Received on February 20, 2009; accepted on December 10, 2009)

\begin{abstract}
$\mathrm{A}_{\mathrm{c}}^{\mathrm{p}}$ produção de palmeiras para uso comercial, visando o paisagismo (exterior e interior) tem-se desenvolvido muito, tornando-se um importante segmento da horticultura ornamental.

Uma das espécies de palmeira muito utilizada no paisagismo é a palmeirarápis [Rhapis excelsa (Thunberg) Henry ex. Rehder], que é muito cultivada no Brasil em vasos, parques e jardins, em locais sombreados ou de meia-sombra, e é de fácil desenvolvimento (Lorenzi \& Souza, 2001).

No estado do Rio de Janeiro, a floricultura é uma atividade que vem se desenvolvendo de maneira expressiva em diversos municípios, destacando-
\end{abstract}

se aqueles das regiões metropolitanas, Costa Verde, e baixadas litorâneas (EMATER-RIO, 2004). Segundo o relatório Projeto Floricultura Fluminense (SEBRAE-FIRJAN-AGRAR, 2003), o cultivo de palmeiras em recipientes, por apresentar boa viabilidade econômica e facilidade de manejo, é uma modalidade com grande potencialidade nos mercados externo e interno.

Dentre os aspectos importantes para o cultivo de plantas em recipientes, destaca-se o substrato. O substrato exerce influência significativa na arquitetura do sistema radicular, no estado nutricional das plantas, bem como no movimento da água no sistema solo-planta-atmosfera.
O cultivo em recipientes, limitando o espaço de crescimento das raízes, requer que o substrato apresente algumas características como boa retenção de umidade, facilidade de rehidratação, porosidade suficiente para permitir as trocas gasosas, suporte ou ancoragem para a planta, alta capacidade de adsorção, boa capacidade de tamponamento, ausência de pragas e patógenos, e alguma reserva de nutrientes (Kämpf, 2000; Hartmann \& Kester, 1975; Röber, 1999).

Um bom substrato para produção de palmeiras em recipientes deve ser bem drenado, bem aerado, e de lenta decomposição, posto que algumas palmeiras permanecem no mesmo recipiente por 
um longo período, com espaço ocupado pelo ar de 10 a $15 \%$ e com capacidade de retenção de água de 30 a 40\% v/v (Broschat \& Meerow, 2000). Meerow (1994 e 1995) indica o potencial de utilização da fibra de coco como substituto da turfa nas misturas para o cultivo de palmeiras.

O objetivo deste trabalho foi avaliar a qualidade e teor de nutrientes de palmeira-rápis (Rhapis excelsa) em substrato com fibra de coco em mistura com substrato comercial.

\section{MATERIAL E MÉTODOS}

Mudas de palmeira-rápis (Rhapis excelsa), com aproximadamente oito meses e sete $\mathrm{cm}$ de altura, oriundas de sementes, foram cultivadas de maio de 2002 a maio de 2004, em casa de vegetação com cobertura de plástico leitoso $100 \mu$ e sombrite ${ }^{\circledR} 30 \%$, e aberturas laterais com sombrite ${ }^{\circledR}$ de $70 \%$, na UENF, em Campos dos Goytacazes-RJ. As plantas foram cultivadas em vasos plásticos pretos, com capacidade para 35 $\mathrm{L}$, contendo uma das misturas de fibra de coco $(0,25,50$ e $75 \%)$ e substrato comercial Plantmax HT $^{\circledR}$, em um experimento com os seguintes tratamentos: $\mathrm{T} 1=0 \% \mathrm{FC} ; \mathrm{T} 2=25 \% \mathrm{FC} ; \mathrm{T} 3=50 \% \mathrm{FC}$; $\mathrm{T} 4=75 \%$ FC, no delineamento de blocos ao acaso, com quatro repetições e três plantas por parcela, sendo uma planta por vaso, totalizando 48 plantas.

O mesocarpo foi preparado conforme descrito por Jasmim et al. (2006). Todas as plantas receberam a mesma adubação, iniciada aos três meses após o plantio, com a formulação de $25 \mathrm{~g}$ de 4-14-8 por vaso, intercalados com 10 $\mathrm{g}$ de uréia por vaso, em intervalos de aproximadamente três meses.

As plantas foram avaliadas quanto ao número de folhas da haste inicial, determinado por contagem; alturas da haste inicial e dos perfilhos (da base do caule à inserção da última folha completamente expandida), medidas por meio de uma trena portátil; número de perfilhos e número de folhas por perfilho, por contagem. Foram feitas 20 medições durante o período experimental de 24 meses.

A matéria seca e os teores de nu- trientes foram determinados em cinco épocas, a saber, 6, 10, 16, 20 e 25 meses após o plantio, retirando-se uma folha recém-expandida da haste inicial de cada vaso, juntando-se as três plantas da parcela, por tratamento em cada bloco.

Para determinação de nutrientes, cada última folha completamente expandida da haste inicial era limpa com algodão umedecido com água desionizada, para retirada de impurezas, e colocada para secar dentro de saco de papel em estufa com ventilação forçada a $70^{\circ} \mathrm{C}$ por um período de 72 horas, e triturada em moinho Wiley, com peneira de 20 mesh. Em seguida, o material vegetal foi submetido às digestões sulfúrica e nitro-perclórica, separadamente, conforme descrito por Malavolta et al. (1997). Os extratos foram utilizados para a determinação dos teores de $(\mathrm{N}$, $\mathrm{P}, \mathrm{K}, \mathrm{Ca}, \mathrm{Mg}$ e S).

O nitrogênio orgânico foi determinado pelo método de Nessler (Jackson, 1965), após a digestão sulfúrica dos materiais; o fósforo pela redução do complexo fosfo-molíbdico pela vitamina C (Braga \& Defelipo, 1974); para nitrogênico nítrico, utilizou-se a metodologia descrita por Cataldo et al. (1975). O cloro foi determinado por titulometria (Malavolta et al., 1997). Os teores de potássio, cálcio e magnésio foram determinados por espectrofotometria de absorção atômica e o enxofre por turbidimetria do sulfato de bário (Malavolta et al., 1997).

O experimento foi implantado segundo delineamento em blocos casualizados com quatro repetições, onde os tratamentos foram todas as combinações entre épocas e teor de FC, a 5\% de probabilidade. Para comparar os teores de FC, utilizou-se a análise de regressão até segundo grau em função de época, também utilizando a 5\% de probabilidade.

A análise de qualidade das mudas de palmeira-rápis foi realizada através do preenchimento por 10 avaliadores de formulários individuais para cada planta, combinando os percentuais de FC e a aceitação para compra pelos critérios "gostei" (muito ou pouco) e "compraria" ( $\operatorname{sim}$ ou não); os resultados foram analisados em intervalo de confiança a $5 \%$ de probabilidade.

\section{RESULTADOS E DISCUSSÃO}

As plantas cultivadas nos diferentes substratos não diferiram significativamente entre si em altura da haste inicial, nem em número de perfilhos, altura de perfilhos e número de folhas dos perfilhos, mas diferiram em número de folhas da haste inicial. A análise de regressão mostrou um efeito quadrático significativo do aumento do percentual de fibra sobre o número de folhas que

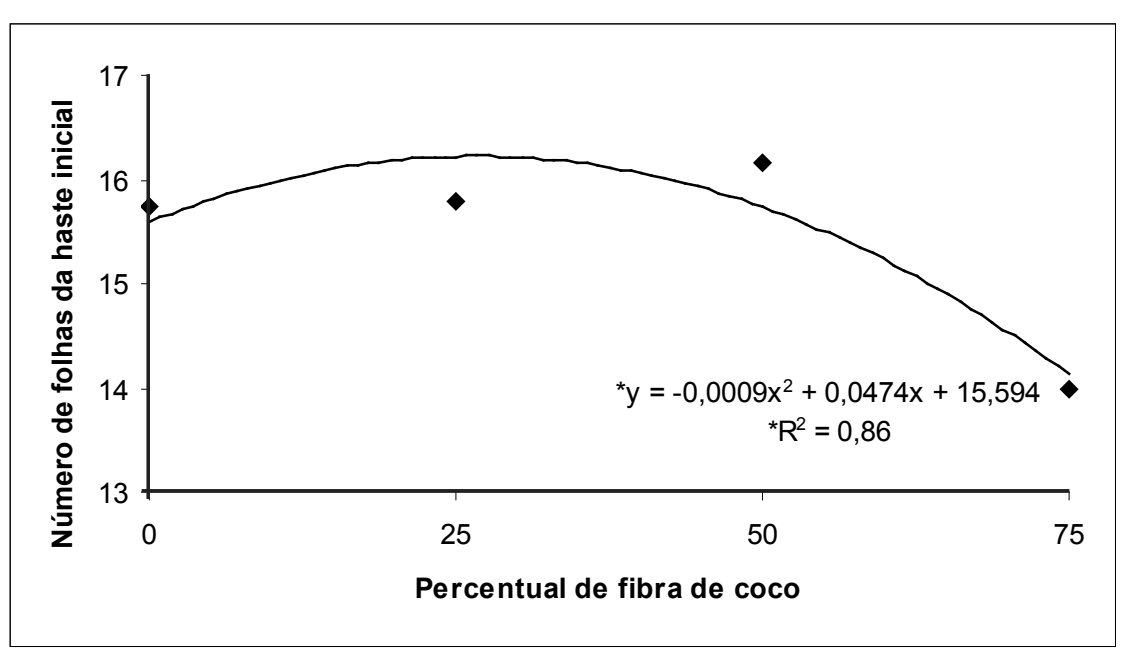

Figura 1. Número de folhas de Rhapis excelsa ao longo do período experimental de 24 meses de cultivo em função do percentual de fibra de $\operatorname{coco}(\mathrm{FC})$ no substrato. ${ }^{*} \mathrm{p} \geq 0,05$ (number of leaves of Rhapis excelsa along an experimental period of 24 months of growth as a function of the percentage of coconut fiber (FC) in the substrate. * $\mathrm{p} \geq 0.05$ ). Campos dos Goytacazes, UENF, 2005. 


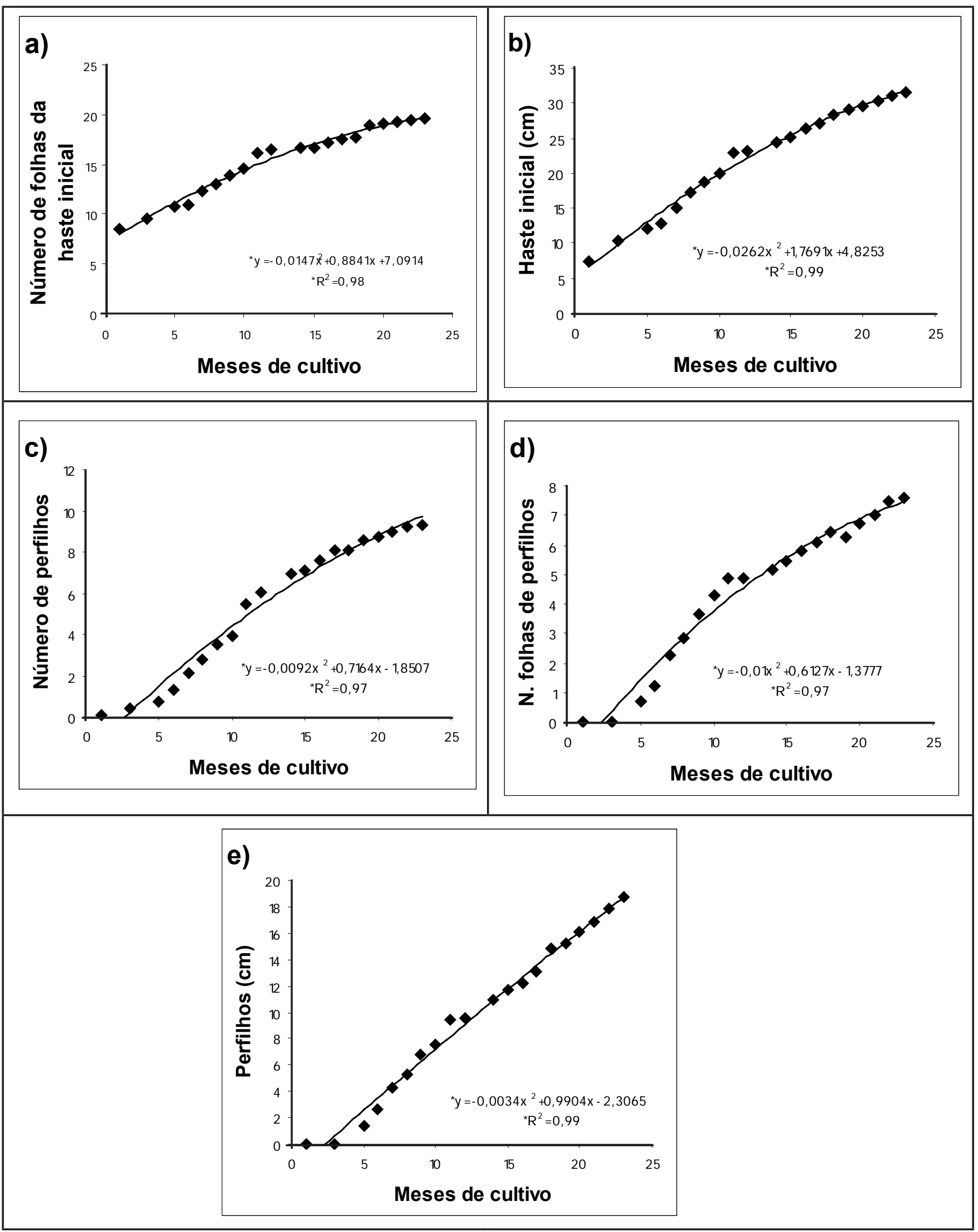

Figura 2. Características de crescimento de Rhapis excelsa em função do tempo de cultivo em meses após o plantio: a) número de folhas da haste inicial; b) altura da haste inicial (cm); c) número de perfilhos; d) número de folhas nos perfilhos; e) altura de perfilhos (cm). * $\mathrm{p} \geq 0,05$ (growth characteristics of Rhapis excelsa as a function of growth period in months after planting: a) number of leaves of the initial stem; b) height of initial stem (cm); c) number of offshoots; d) number of leaves of offshoots; e) height of offshoots (cm). $\left.{ }^{*} \mathrm{p} \geq 0.05\right)$. Campos dos Goytacazes, UENF, 2005. 
Tabela 1. Teores de nutrientes $\left(\mathrm{g} \mathrm{kg}^{-1}\right)$ na matéria seca das folhas de Rhapis excelsa ao longo do período experimental de 24 meses de cultivo (leaf dry matter nutrient contents of Rhapis excelsa along an experimental period of 24 months of growth). Campos dos Goytacazes, UENF, 2005.

\begin{tabular}{lcccc}
\hline \multirow{2}{*}{ Nutrientes } & \multicolumn{4}{c}{ Tratamentos } \\
\cline { 2 - 5 } & $\mathbf{0 \%} \mathbf{~ F C}$ & $\mathbf{2 5 \%} \mathbf{~ F C}$ & $\mathbf{5 0 \%} \mathbf{~ F C}$ & $\mathbf{7 5 \%} \mathbf{~ F C}$ \\
\hline $\mathrm{N}$ & 18,29 & 17,80 & 17,93 & 18,29 \\
$\mathrm{NO}_{3}$ & 0,81 & 0,80 & 0,66 & 0,72 \\
$\mathrm{P}$ & 2,16 & 2,04 & 2,02 & 2,34 \\
$\mathrm{~K}$ & 19,96 & 20,40 & 18,74 & 18,11 \\
$\mathrm{Cl}$ & 13,84 & 11,89 & 11,63 & 13,74 \\
$\mathrm{Ca}$ & 3,97 & 2,75 & 2,69 & 4,04 \\
$\mathrm{~S}$ & 1,80 & 1,61 & 1,77 & 2,07 \\
$\mathrm{Mg}$ & 2,22 & 1,98 & 2,08 & 2,64 \\
\hline
\end{tabular}

$\mathrm{FC}=$ fibra de coco (coconut fiber)

apresentou ponto de máximo estimado de 16 folhas nas plantas cultivadas em substrato com 26\% de fibra (Figura 1). Os resultados do número de folhas da haste inicial das plantas aos 24 meses de cultivo diferem daqueles observados por Jasmim \& Alves (2003) que não encontraram diferenças no número de folhas da haste inicial das plantas dos diferentes tratamentos aos seis meses de cultivo.

Todas as características de crescimento avaliadas variaram significativamente em função do número de meses decorridos no período experimental, independentemente do substrato utilizado (Figura 2a, b, c, d, e) e não foram observadas interações entre substratos e épocas de avaliação.

Os valores das médias de altura da haste inicial, observados aos seis meses de cultivo são próximos àqueles encontrados por Luz et al. (2006) para o mesmo período de cultivo (médias de 12,60 a $15,40 \mathrm{~cm}$ ), estudando o efeito de diferentes alturas de recipientes no cultivo de palmeira-rápis. Entretanto, os valores máximos de altura da haste inicial, observados no presente trabalho, não são tão elevados, em termos absolutos, quanto os encontrados por aqueles

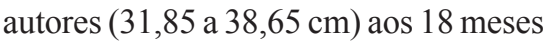
de cultivo. Porém, no trabalho de Luz et al. (2006), as plantas não apresentaram perfilhamento, enquanto no presente as hastes principais perfilharam e houve crescimento destes perfilhos em número, altura e número de folhas, bem maior que aquele observado na haste inicial, podendo esse fato ter restringido o crescimento da haste inicial.

Através da derivação das equações de regressão, estimou-se o número de meses para as plantas de palmeira-rápis atingirem o crescimento máximo, no mesmo recipiente e nas mesmas condições de cultivo, permitindo-se desta forma julgar qual seria o momento mais propício para a mudança de recipiente. Assim, o crescimento máximo estimado foi de 20 folhas em 30 meses para o número de folhas da haste inicial; 35 cm em 34 meses para a altura da haste inicial; 12 perfilhos em 40 meses para o número de perfilhos; 8 folhas em 31 meses para o número de folhas de perfilhos; e $70 \mathrm{~cm}$ em 146 meses para a altura dos perfilhos.

Na avaliação da qualidade das plantas, observou-se que o maior percentual de entrevistados gostou muito das plantas e as compraria (Figura 03b), tendo maior aceitação, as plantas cultivadas em 50\% FC e 50\% SC (Figura 03a). Apesar de esse substrato ter apresentado o melhor resultado na avaliação da qualidade, as plantas cultivadas nos substratos com outros percentuais de FC e SC também estavam dentro do padrão de comercialização, ou seja, sendo igualmente aceitas no comércio local, e não foram descartadas. Esteticamente, todas as plantas estavam vigorosas, sadias, com grande número de folhas e perfilhos, com a coloração das folhas verde brilhante, o que chamava a atenção dos entrevistados. Assim, as características de qualidade confirmam os resultados da análise de crescimento, que indicam a adequação da adição dos diferentes percentuais de fibra de coco ao substrato sem prejuízo na qualidade do produto.

As razões para gostarem muito das plantas e não comprá-las, mesmo em menor percentual, variou entre os entrevistados, como, por exemplo, o porte grande da planta, a não preferência pela espécie, entre outros.

Não foram observados sintomas visuais de deficiência de nutrientes nas plantas. Na Tabela 1 estão os teores de nutrientes na matéria seca das folhas de palmeira-rápis ao longo do período experimental de 24 meses de cultivo.

A análise de regressão não mostrou diferenças significativas nos teores de $\mathrm{N}, \mathrm{NO}^{-3}, \mathrm{Ca}, \mathrm{Mg}$ e $\mathrm{S}$ das folhas das plantas em função do percentual de FC no substrato de cultivo e nem em função do número de meses de cultivo ao longo do período experimental; as médias originais estão na Tabela 1. Os valores desses nutrientes observados em todas as plantas estão dentro da faixa de teores foliares descrita por Jones et al. (1991) como adequada para a espécie, com exceção do Ca que apresentou valores abaixo do considerado adequado pelo autor. Os valores observados para $\mathrm{Ca}$, bem como para os demais nutrientes, podem ser considerados adequados uma vez que não foram observados sintomas visuais de deficiência em nenhuma das plantas.

Diferentemente dos resultados dos teores de $\mathrm{N}$ e Ca descritos, Amaral (2007) observou menores teores foliares de N em Vriesea gigantea em função do aumento da FC no substrato (30, 40, 50, $60,70,80,90$ e $100 \%$ de FC) e maiores teores foliares de $\mathrm{Ca}$ em Aechmea ramosa x fulgens nas mesmas condições; porém, não observou diferenças entre os teores foliares de $\mathrm{Mg}, \mathrm{NO}^{-3}$ e $\mathrm{S}$ das mesmas plantas.

Os teores foliares de $\mathrm{P}$ variaram significativamente em função do percentual de FC no substrato. A equação de regressão, $\mathrm{y}=0,0002 \mathrm{x}^{2}-0,0114 \mathrm{x}+$ $2,1727\left(\mathrm{R}^{2}=0,95\right)$, mostra que os teores foliares de $\mathrm{P}$ nas plantas cultivadas no substrato com $25 \%$ de FC foram menores que nas plantas do substrato sem $\mathrm{FC}$, e que os maiores teores foliares de $\mathrm{P}$ 


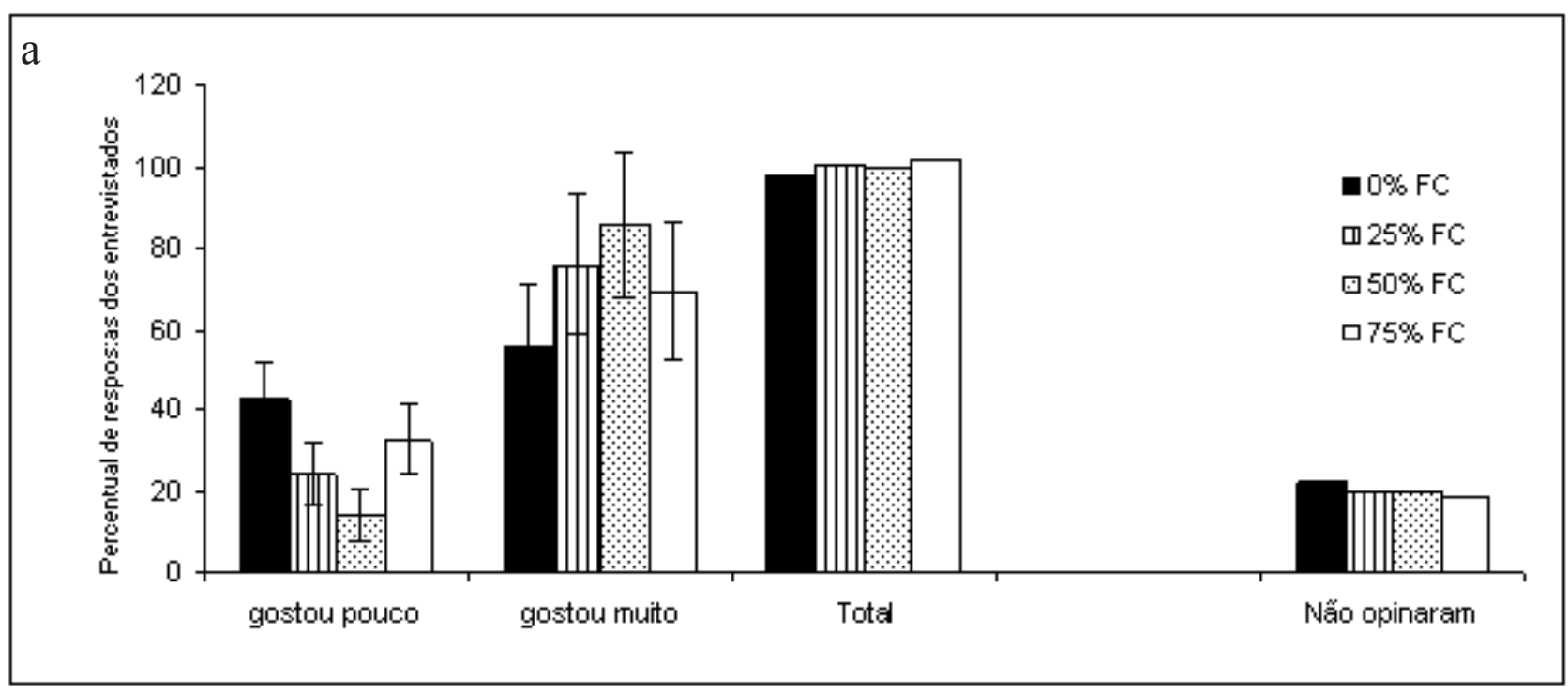

b

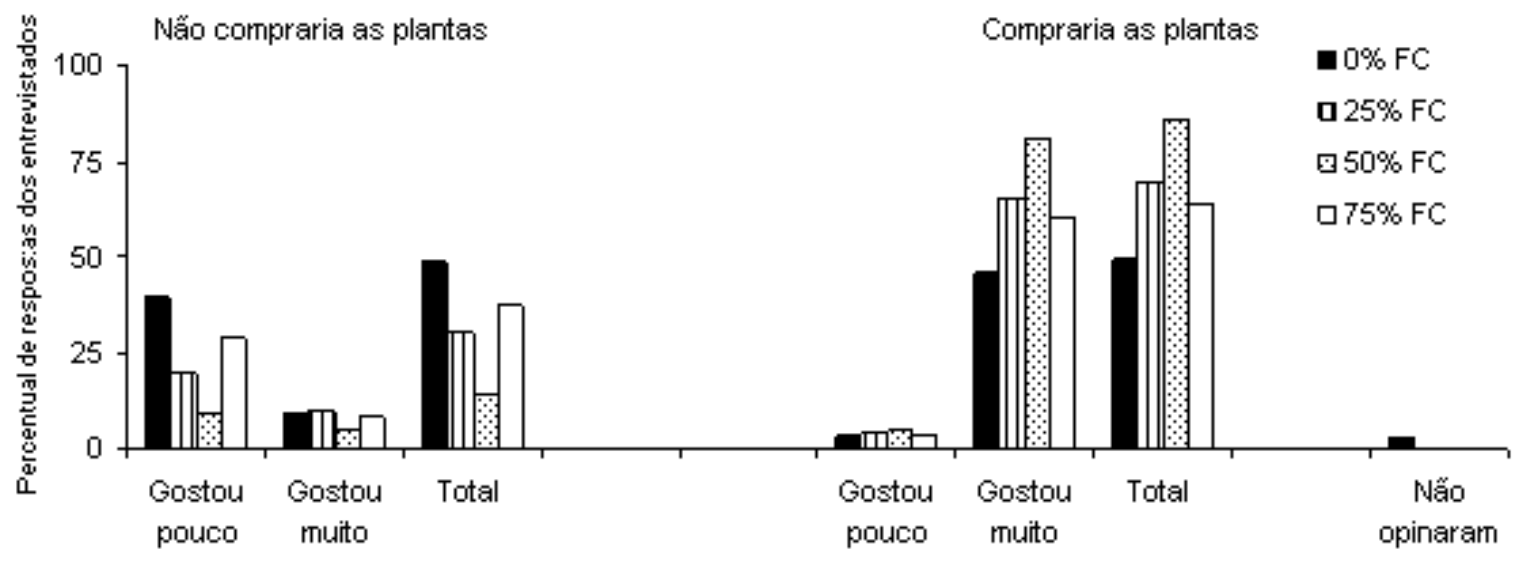

Figura 3. Qualidade das mudas de Rhapis excelsa cultivadas em substrato composto 0, 25, 50 e 75\% de fibra de coco (FC) e substrato comercial (SC) Plantmax HT ${ }^{\circledR}$ : a) com base na aceitação pelos entrevistados; b) com base na avaliação visual e perspectiva de aquisição pelos entrevistados. ${ }^{*} \mathrm{p} \geq 0,05$ (quality of Rhapis excelsa plants grown in substrate consisting of $0,25,50$ and $75 \%$ of coconut fiber (FC) and commercial substrate (SC) Plantmax HT $^{\circledR}$ : a) base on the acceptance of the interviewed people; b) based on the visual evaluation and acquisition perspective of the interviewed people. $\left.{ }^{*} \mathrm{p} \geq 0.05\right)$. Campos dos Goytacazes, UENF, 2005.

foram observados nas plantas cultivadas em $75 \%$ de FC, embora todos os valores de teores foliares de $\mathrm{P}$ estejam dentro da faixa considerada adequada (Jones et al., 1991).

Esses resultados diferem daqueles observados por Jasmim \& Alves (2003) que não encontraram diferenças significativas entre os teores foliares de $\mathrm{P}$ em plantas de Rhapis excelsa, aos seis meses de cultivo, e de Ravenala madagascariensis em substratos contendo 0 , 25,50 e $75 \%$ de FC.

Nos teores foliares de $\mathrm{K}$ foram ob- servadas diferenças significativas ( $\mathrm{y}=$ $\left.-0,0288 x+20,383 ; R^{2}=0,77\right)$ em função do percentual de FC no substrato, com decréscimo nos teores desse nutriente à medida que se aumentou o percentual de FC, apresentando os valores mais baixos com $75 \%$ de FC. Não foram observadas interações significativas. Os teores foliares de $\mathrm{K}$ observados estão dentro da faixa considerada adequada (Jones et al., 1991).

A alta concentração de $\mathrm{K}$ no substrato com FC, decorrente de altas concentrações presentes na fibra de coco, não afetou a sua disponibilidade para o crescimento das plantas cultivadas nos substratos com maiores percentuais de fibra, como também foi observado por Souza (2002) e Amaral (2003) em singônio e Quesnelia quesneliana (Bromeliaceae), respectivamente. Da mesma forma Jasmim \& Alves (2003) observaram que os teores foliares de $\mathrm{K}$ em palmeira-rápis não aumentaram em função do aumento da fibra de coco no substrato nas plantas de palmeira-rápis, aos seis meses de cultivo.

De acordo com a análise dos resul- 
tados, pode-se concluir que a fibra de coco poderá compor o substrato para a produção de palmeira-rápis nos percentuais de 25 a 75\%, com melhor aceitação pelos entrevistados àquelas cultivadas em $50 \%$ FC e $50 \%$ SC. Não houve sintoma visual de deficiência de nutrientes em nenhuma das plantas, cujos teores foliares encontrados em plantas sadias com padrão de comercialização foram de: 17,80 - 18,29 $\mathrm{g} \mathrm{kg}^{-1}$ de N; 0,66 - 0,81 $\mathrm{g} \mathrm{kg}^{-1}$ de $\mathrm{NO}^{-3} ; 2,02$ - 2,34 $\mathrm{g} \mathrm{kg}^{-1}$ de P; 18,11 - 20,40 $\mathrm{g} \mathrm{kg}^{-1}$ de K; 11,63 - 13,84 $\mathrm{g} \mathrm{kg}^{-1}$ de $\mathrm{Cl} ; 2,69$ - 4,04 $\mathrm{g} \mathrm{kg}^{-1}$ de $\mathrm{Ca}$; 1,61 - 2,07 $\mathrm{g} \mathrm{kg}^{-1}$ de S; 1,98 - 2,64 g $\mathrm{kg}^{-1}$ de $\mathrm{Mg}$.

\section{AGRADECIMENTOS}

Nossos agradecimentos à FAPERJ, Setor de Nutrição Mineral de Plantas, LFIT-CCTA da UENF.

\section{REFERÊNCIAS}

AMARAL TL. 2003. Aplicação de benzilaminopurina (BAP) e de nitrogênio em Quesnelia quesneliana Brongniart cultivada em diferentes substratos. Campos dos Goytacazes-RJ: UENF. 50p (Tese mestrado).

AMARAL TL. 2007. Substratos com fibra de coco e fungos micorrizicos no cultivo de bromélias. Campos dos Goytacazes-RJ:
UENF. 181p (Tese doutorado).

BRAGA JM; DEFELIPO BV. 1974. Determinação espectrofotométrica de fósforo em extratos de solos e material vegetal. Revista Ceres 21: 73-85.

BROSCHAT TK; MEEROW AW. 2000. Ornamental Palm Horticulture. University Press of Florida. 256p.

CATALDO DA; HAROON M, SCHADER LE; YOUNG UL. 1975. Rapid colorimetric determination of nitrate in plant tissue by nitration of salicylic acid. Communication in Soil Science and Plant Analyses 6: 71-80.

EMATER-RIO. 2004. Censo de Floricultura no Estado do Rio de Janeiro, Secretaria de Agricultura. Niterói, RJ, Brasil (CD-ROM).

HARTMANN HT; KESTER DE. 1975. Plant Propagation, principles and practices. 3. ed. New Jersey: Prentice-Hall. 662p.

JACKSON ML. 1965. Soil Chemical analysis. 5. ed. Englewood Cliffs: N.J. USA Prentice-Hall Inc. $498 \mathrm{p}$

JASMIM J; ALVES FS. 2003. Growth of traveler's tree and lady palm in coconut mesocarp. Proceedings of the Interamerican Society for Tropical Horticulture. Miami, FL . 47: 31-34.

JASMIM JM; TOLEDO RRV; CARNEIRO LA; MANSUR E. 2006. Fibra de coco e adubação foliar no crescimento e na nutrição de Cryptanthus sinuosus. Horticultura Brasileira 24: 309-314.

JONES JB; WOLF B; MILLS HA. 1991. Plant Analysis Handbook. A practical sampling, preparation, analysis, and interpretation guide. Athens, Georgia: USA Micro-Macro Publishing Inc. 213p.

KÄMPF AN. 2000. Produção comercial de plantas ornamentais. Guaíba: Agropecuária. $254 \mathrm{p}$.
LORENZI H; SOUZA HM. 2001 Plantas ornamentais no Brasil: arbustivas, herbáceas e trepadeiras. Nova Odessa, SP: Instituto Plantarum. 871p.

LUZ PB; AGUIAR FFA; TAVARES AR; KANASHIRO S; AGUIAR J; NASCIMENTO TDR. 2006. Desenvolvimento de Rhapis excelsa (Thunberg) Henry Ex. Rehder (Palmeira-Ráfia): influência da altura do recipiente na formação de mudas. Ciência Agrotécnica. 30: 31-34.

MALAVOLTA E; VITTI GC; OLIVEIRA SA. 1997. Avaliação do estado nutricional das plantas. Princípios e aplicações. Piracicaba: Associação Brasileira para Pesquisa da Potassa e do Fosfato (POTAFOS). 319p.

MEEROW AW. 1994. Growth of two subtropical ornamentals using coir (coconut mesocarp pith) as a peat substitute. Hortscience 29: 1484-1486.

MEEROW AW. 1995 Growth of two tropical foliage plants using coir dust as a container medium amendment. Hort Technology 5: 237-239.

RÖBER R. 1999. Substratos Hortícolas: possibilidades e limites de sua composição e uso; exemplos da pesquisa, da indústria e do consumo. In: KÄMPF NA; FERMINO MH. Substratos para plantas: a base da produção vegetal em recipientes. 1. ed. Porto Alegre: Gênesis. p.123-138.

SEBRAE-FIRJAN-AGRAR. 2003. Oportunidade de investimento em flores e plantas ornamentais no Estado do Rio de Janeiro. Rio de Janeiro. 92p (CD-ROM).

SOUZA NA. 2002. Utilização do mesocarpo de coco verde na produção de tutores e substrato para o cultivo de singônio (Syngonium angustatum Schott). Campos dos GoytacazesRJ: UENF. 52p (Tese mestrado). 